National Water-Quality Assessment (NAWQA) Program, National Synthesis on Volatile Organic Compounds (VOCs)

\title{
Quality of Methyl tert-Butyl Ether (MTBE) Data for Ground-Water Samples Collected during 1993-95 as part of the National Water-Quality Assessment Program
}

This fact sheet presents information for assessing the quality of methyl tertbutyl ether (MTBE) data collected from ground water during 1993-95 as part of the U.S. Geological Survey's (USGS) National Water-Quality Assessment (NAWQA) Program. Results indicate that the ground-water samples collected during 1993-95 are not positively biased due to sample contamination. Results also indicate favorable recovery of $M T B E$ in ground-water samples and precise analyses.

\section{Introduction}

The Clean Air Act Amendments of 1990 mandated that oxygen-containing compounds be added to gasoline to abate air pollution in areas where concentrations of ozone in the summer or carbon monoxide in the winter exceed established air-quality standards (Zogorski and others, 1997). These compounds are called oxygenates, and they also have been added to gasoline in the United States since the late 1970 's to increase the octane level of gasoline. MTBE is the most commonly used oxygenate because of its low cost, ease of production, and favorable transfer and blending characteristics (Squillace and others, 1996).

Methyl tert-butyl ether has been detected in ground water, surface water, snow, and the atmosphere (Bruce and McMahon, 1996; Delzer and others, 1996; Squillace and others, 1996;
Zogorski and others, 1997). Of 60 volatile organic compounds (VOCs) analyzed, MTBE was the second most frequently detected VOC in shallow ground-water samples collected from eight urban areas during 1993-94 as part of the NAWQA Program (Squillace and others, 1996).

The primary objectives of the NAWQA Program are to: (1) describe current water-quality conditions for a large part of the Nation's freshwater streams, rivers, and aquifers;

(2) describe how water quality is changing over time; and (3) improve understanding of the primary natural and human factors that affect water-quality conditions. These objectives are being achieved through investigations of 59 of

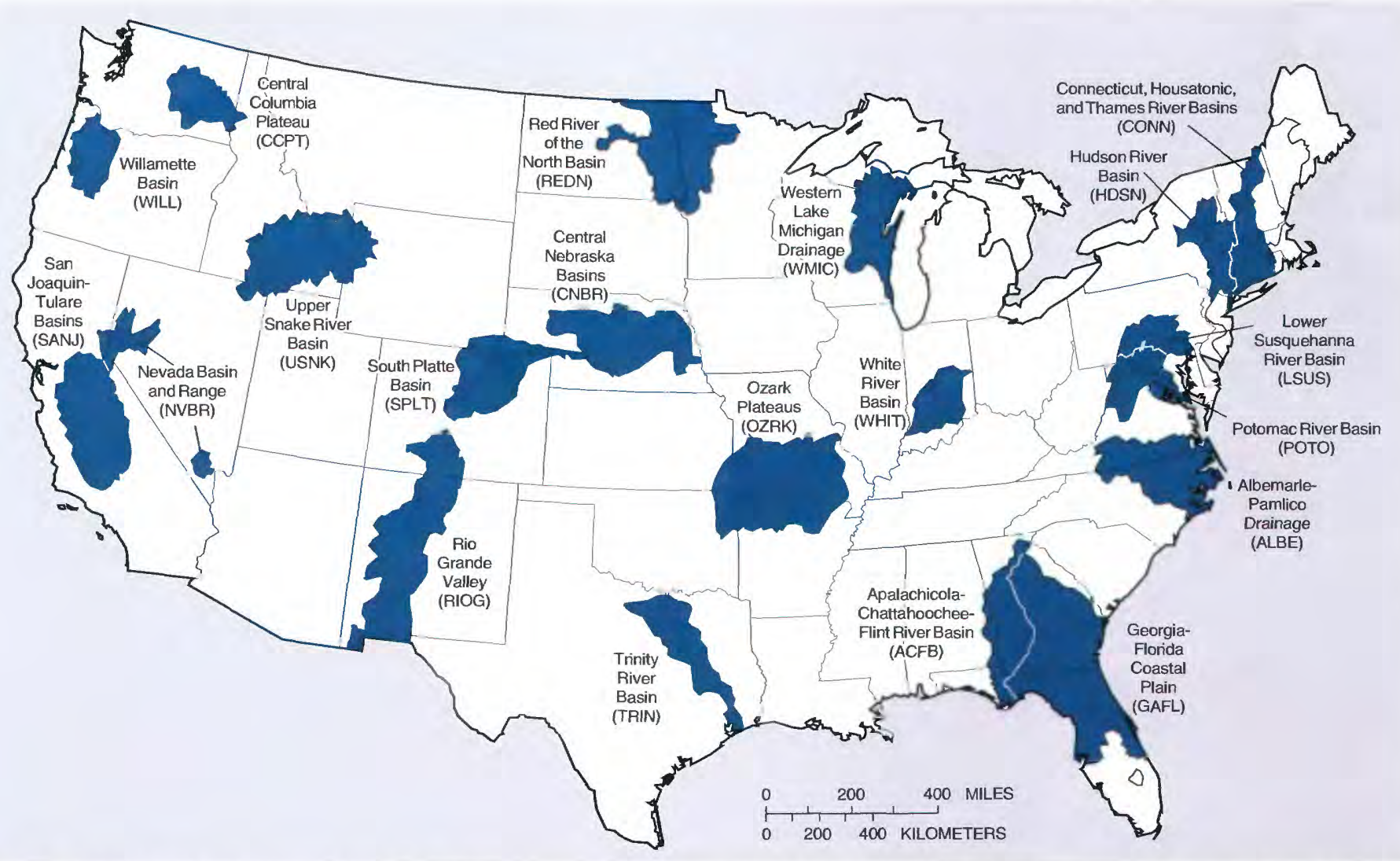

Figure 1. Location of 20 National Water-Quality Assessment Program study units that contributed to the data analyzed in this report. 
the Nation's most important river basins and aquifer systems, referred to as study units. Water-quality data were collected during 1993-95 in 20 of the 59 study units (fig. 1).

Ground-water samples collected as part of the NAWQA Program for the analysis of MTBE and other VOCs during 1993-95 were analyzed at the USGS National Water Quality Laboratory (NWQL) by purge and trap capillary gas chromatography/mass spectrometry (Rose and Schroeder, 1995). Laboratory quality-control data indicated favorable analytical performance. Laboratory reagent blanks were routinely analyzed with each set of water samples; MTBE was not detected in any of these samples. Reagent water spiked with MTBE and other VOCs was also analyzed with each set of samples. The accuracy and precision of these MTBE analyses were within accepted limits of 80 to 120 percent, with a relative standard deviation of less than 20 percent (Raese and others, 1995; U.S. Environmental Protection Agency, 1992, p. 20).

The purpose of this fact sheet is to summarize MTBE field quality-control data associated with ground-water samples collected during 1993-95 as part of the NAWQA Program. Specific qualitycontrol data presented include fieldblank, equipment-blank, trip-blank, field matrix-spike, and sequential duplicate samples.

\section{Quality of MTBE Data for Ground- Water Samples}

To aid in the interpretation of waterquality data collected as part of the NAWQA Program, a quality-assurance plan was developed and followed to guide data-collection methods, recommended procedures, and work plans and schedules (Koterba and others, 1995). As part of this plan, quality-control samples were collected routinely to measure the magnitude of bias and variability of the data-collection process. Both the field processes of sample collection and transport to the laboratory and the laboratory processes of sample preparation and analysis are evaluated.

\section{Types of Quality-Control Samples}

Quality-control samples are used to characterize bias and variability within specific elements of the data-collection process. Bias, which can be either positive or negative, is the systematic error in a method. Sample contamination is one of the most common sources of positive bias affecting environmental samples. Matrix interference, degradation or other loss mechanisms, and chemical hydrolysis also contribute to bias affecting environmental samples. Variability, however, is the degree of random error in independent measurements of the same quantity (Mueller, 1998). Variability results from errors in collecting and processing samples in the field and errors in laboratory procedures.

The ground-water and quality-control data used in this fact sheet were retrieved from the NAWQA national data base. This data base was populated with data from each respective study unit. Additional verification of these data was completed by the individual study units to further assure accuracy. Table 1 lists the number of ground-water samples and quality-control samples collected during 1993-95 within the 20 NAWQA study units (fig. 1). A total of 415 qualitycontrol samples were collected to assess the bias and variability of the NAWQA MTBE ground-water data collected during 1993-95.
Blanks were used to assess positive bias in environmental samples due to contamination. These were prepared using a blank solution that was free of the analytes of interest. Any measured concentration in a blank sample that was not present in the blank solution was believed to be due to contamination. Three types of blank samples were routinely collected-field blanks, equipment blanks, and trip blanks. A total of 214 field blanks were prepared in the field by subjecting a blank solution to all aspects of sample collection, processing, preservation, transport, and laboratory analysis. Field blanks are intended to measure all possible sources of positive bias. Twenty-one equipment blanks were prepared in the same fashion as the field blank; however, these blanks were collected under controlled conditions, such as in an office or laboratory. Equipment blanks are generally prepared prior to initiating sampling programs to ensure that the cleaning protocols are adequate to fully clean the sampling equipment. Sixteen trip blanks were prepared at the laboratory and sent to the field where they were transported with the sampling crews and kept with the set of environmental samples before, during, and after

Table 1. Number of ground-water and quality-control samples collected during 1993-95 within 20 NAWQA study units

\begin{tabular}{lrrrrrr}
\hline $\begin{array}{c}\text { Study unit } \\
\text { acronym } \\
\text { (fig. 1) }\end{array}$ & $\begin{array}{c}\text { Ground-water } \\
\text { samples }\end{array}$ & Field & $\begin{array}{c}\text { Equip- } \\
\text { ment }\end{array}$ & Trip & $\begin{array}{c}\text { Field } \\
\text { matrix-spike } \\
\text { samples }\end{array}$ & $\begin{array}{c}\text { Sequential } \\
\text { duplicate } \\
\text { samples }\end{array}$ \\
\hline ACFB & 118 & 17 & 0 & 0 & 11 & 3 \\
ALBE & 94 & 15 & 3 & 0 & 1 & 5 \\
CCPT & 160 & 15 & 1 & 3 & 6 & 1 \\
CNBR & 10 & 3 & 0 & 0 & 0 & 1 \\
CONN & 201 & 31 & 0 & 2 & 3 & 1 \\
GAFL & 103 & 4 & 1 & 0 & 3 & 9 \\
HDSN & 85 & 6 & 1 & 0 & 1 & 4 \\
LSUS & 118 & 14 & 1 & 0 & 12 & 0 \\
NVBR & 148 & 13 & 3 & 1 & 1 & 5 \\
OZRK & 54 & 4 & 0 & 0 & 2 & 2 \\
POTO & 16 & 2 & 1 & 0 & 2 & 2 \\
REDN & 38 & 0 & 2 & 0 & 0 & 0 \\
RIOG & 108 & 11 & 0 & 0 & 11 & 0 \\
SANJ & 127 & 18 & 2 & 1 & 17 & 1 \\
SPLT & 166 & 17 & 0 & 0 & 13 & 3 \\
TRIN & 108 & 9 & 0 & 0 & 4 & 4 \\
USNK & 130 & 13 & 5 & 1 & 17 & 0 \\
WHIT & 101 & 9 & 1 & 2 & 2 & 7 \\
WILL & 75 & 6 & 0 & 0 & 3 & 0 \\
WMIC & 84 & 7 & 0 & 6 & 6 & 1 \\
Total & 2,044 & 214 & 21 & 16 & 115 & 49 \\
\hline & & & & & & 1 \\
\hline
\end{tabular}


sample collection. Trip-blank samples were never opened in the field and are intended to measure contamination occurring during transport and analysis at the laboratory.

Bias can be further characterized by the collection of field matrix-spike samples. A total of 115 field matrix-spikes were prepared by adding a known concentration of MTBE to the environmental sample in such a manner as to minimize the change in the matrix of the original sample. Results were interpreted in terms of percent recovery, calculated as follows:

$$
\text { Percent recovery }=\frac{\left(C_{\text {spiked }}-C_{\text {unspiked }}\right)}{C_{\text {expd }}} \times 100,
$$

where

$$
\begin{gathered}
\mathrm{C}_{\text {spiked }} \begin{array}{c}
\text { is the concentration measured } \\
\text { in the spiked sample, in } \\
\text { micrograms per liter; }
\end{array} \\
\mathrm{C}_{\text {unspiked }} \text { is the concentration measured } \\
\text { in the corresponding } \\
\text { unspiked sample, in micro- } \\
\text { grams per liter; and } \\
\mathrm{C}_{\text {expd }} \text { is the expected or theoretical } \\
\text { concentration of the spiked } \\
\text { sample, in micrograms per } \\
\text { liter. }
\end{gathered}
$$

A total of 49 sequential duplicate samples were collected such that the samples were thought to be essentially identical in composition. These samples were collected one after the other over a short period of time and were intended to estimate bias and variability of the sample-collection, transport, and analytical process (Horowitz and others, 1994).

\section{Bias and Variability of MTBE Data}

A total of 2,044 ground-water samples from urban and agricultural wells were collected. MTBE was detected in 8.8 percent $(179$ of 2,044$)$ of these samples at a minimum reporting limit of 0.20 micrograms per liter $(\mu \mathrm{g} / \mathrm{L})$. Concentrations ranged from 0.20 to $23,000 \mu \mathrm{g} / \mathrm{L}$, with a median detected concentration of $1.0 \mu \mathrm{g} / \mathrm{L}$. Zogorski and others (1998) have previously reported much of these data.

Methyl tert-butyl ether was detected in 0.9 percent ( 2 of 214 ) of field blanks collected during 1993-95; concentrations were 0.30 and $1.7 \mu \mathrm{g} / \mathrm{L}$. Both of these detections occurred in samples from the CCPT study unit. However, study unit personnel indicated that a gasoline can was spilled just before the collection of the $1.7-\mu \mathrm{g} / \mathrm{L}$ field blank. The other detection $(0.30 \mu \mathrm{g} / \mathrm{L})$ occurred about 10 months later and is considered a random occurrence of contamination of MTBE in a field blank. MTBE was not detected in any ground-water sample collected immediately before or after these two field blanks. MTBE was not detected in any of the 21 equipment blanks or 16 trip blanks. Because detection of MTBE in ground-water samples was much more frequent ( 9.8 times) than detection in field blanks, contamination is relatively unimportant for assessing detection frequency. Although contamination may have been as much as $1.7 \mu \mathrm{g} / \mathrm{L}, 40.8$ percent ( 73 of 179 ) of detected concentrations in ground water were greater than $1.7 \mu \mathrm{g} / \mathrm{L}$. Detections of MTBE in the range of 0.20 to $1.7 \mu \mathrm{g} / \mathrm{L}$ occurred 5.9 times more frequently in ground-water samples than in field blanks. The greater frequency and magnitude of detections in ground-water samples indicate that the vast majority of the NAWQA MTBE data are unaffected by contamination.

Field matrix-spike samples were prepared using a 100-microliter fixedvolume micropipet. A separate study completed by the USGS NWQL to evaluate the recovery and variability of the spiking procedure indicated that the micropipet provides a significant source of negative bias in VOC field matrixspike samples, making it extremely difficult to interpret bias due to matrix interference or analyte degradation (P.F. Rogerson, U.S. Geological Survey, written commun., 1996); this fact sheet does not address these potential sources of bias. In the NWQL study, the average recovery of MTBE was 78 percent ( 9 percent relative standard deviation) for ground-water field matrix-spike samples collected by eight NAWQA sampling crews from seven separate locations throughout the United States. Although the micropipet hinders the interpretation of matrix interference and degradation, data collected during 1993-95 within NAWQA study units do provide insight into the recovery of MTBE in ground-water samples. To reduce the bias associated with the use of the micropipet, the USGS currently (1999) uses a 25-microliter syringe to process field matrix-spike samples.

Methyl tert-butyl ether was detected in 100 percent (115 of 115) of the field matrix-spike samples. MTBE was spiked into ground-water samples using the micropipet to achieve an expected concentration of $2.5 \mu \mathrm{g} / \mathrm{L}$. One-hundred thirteen of the 115 field matrix-spike samples did not contain MTBE in the corresponding unspiked ground-water sample above $6.3 \mu \mathrm{g} / \mathrm{L}, 103$ of which did not contain MTBE above the minimum reporting level of $0.20 \mu \mathrm{g} / \mathrm{L}$. The two remaining samples contained MTBE in the unspiked ground-water sample greater than $800 \mu \mathrm{g} / \mathrm{L}$. MTBE concentrations are reported with two significant figures (Rose and Schroeder, 1995). Thus, concentrations in the unspiked sample above $100 \mu \mathrm{g} / \mathrm{L}$ may result in large differences in percent recovery due to analytical reporting protocols. Therefore, only the 113 field matrix-spike samples that did not contain MTBE in the unspiked ground-water sample above $6.3 \mu \mathrm{g} / \mathrm{L}$ are presented in this fact sheet.

Recoveries of MTBE in field matrixspike samples ranged from 36 to 228 percent (fig. 2 ), with median and average recoveries of 80 and 88 percent, respectively. More than 70 percent of these spiked samples had a percent recovery between 60 and 90 . Ten of the

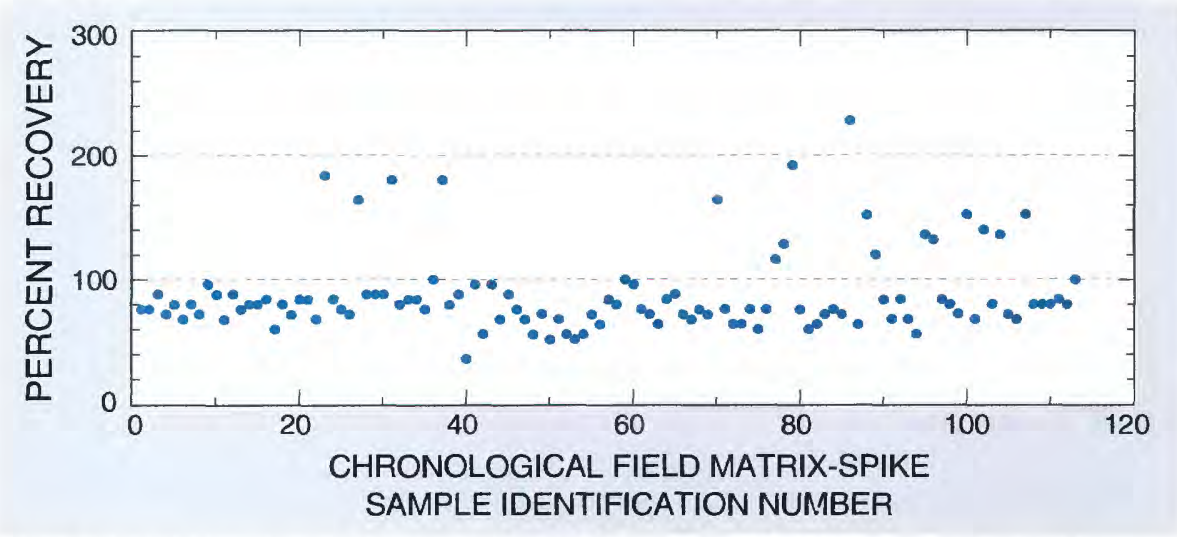

Figure 2. Field matrix-spike recoveries for 113 ground-water samples spiked to achieve an expected concentration of $2.5 \mu \mathrm{g} / \mathrm{L}$. 
113 field matrix-spike samples had percent recoveries greater than 150 . It is possible that these samples were double spiked in the field inadvertently, resulting in spiked-sample concentrations two times the expected concentration; however, this cannot be verified. The median and average recoveries of 80 and 88 percent, respectively, in the NAWQA samples compares favorably to the 78-percent average recovery in the NWQL micropipet study. The negative bias in field matrix-spike recovery most likely is a result of the significant negative bias produced by the micropipet.

Forty-nine sequential duplicate samples were collected. Forty-four of the 49 duplicate samples did not contain MTBE in either sample at concentrations greater than the minimum reporting limit of $0.20 \mu \mathrm{g} / \mathrm{L}$. When detected, MTBE was present in both duplicate samples with very favorable precision (table 2 ). The relative percent difference ranged from 0.0 to 9.5 , with a median of 0.0 .

Table 2. Summary of sequentially collected duplicate pairs that contained MTBE at detectable concentrations in samples collected during 1993-95 within 20 NAWQA study units

$[\mu \mathrm{g} / \mathrm{L}$, microgram per liter; RPD, relative percent difference]

\begin{tabular}{|c|c|c|c|c|c|}
\hline \multirow{3}{*}{$\begin{array}{c}\text { Study } \\
\text { unit } \\
\text { acro- } \\
\text { nym } \\
\text { (fig. 1) }\end{array}$} & \multicolumn{4}{|c|}{ MTBE concentration $(\mu \mathrm{g} / \mathrm{L})$} & \multirow{3}{*}{$\begin{array}{l}\text { RPD } \\
(\%)\end{array}$} \\
\hline & \multicolumn{2}{|c|}{$\begin{array}{l}\text { Duplicate } \\
\text { sample }\end{array}$} & \multirow{2}{*}{$\begin{array}{c}\text { Aver- } \\
\text { age }\end{array}$} & \multirow{2}{*}{$\begin{array}{l}\text { Differ- } \\
\text { ence }\end{array}$} & \\
\hline & 1 & 2 & & & \\
\hline HDSN & 0.20 & 0.20 & 0.20 & 0 & 0 \\
\hline NVBR & 13 & 13 & 13 & 0 & 0 \\
\hline SPLT & 590 & 590 & 590 & 0 & 0 \\
\hline SPLT & 710 & 650 & 680 & 60 & 8.8 \\
\hline SPLT & 600 & 660 & 630 & 60 & 9.5 \\
\hline
\end{tabular}

The infrequent detections of MTBE in blank samples indicates that groundwater samples are not positively biased due to contamination. The significant bias associated with the micropipet limits any assessment of negative bias due to matrix interference, degradation, or other loss mechanisms. However, the detection of MTBE in every field matrixspike sample collected during 1993-95 and similar percent recoveries when compared to a separate NWQL field matrix-spike study, as well as duplicate samples with small relative percent differences, does indicate a favorable recovery of MTBE in ground-water samples. The results of quality-control data analysis for ground-water samples collected during 1993-95 will provide a basis for comparison with qualitycontrol data from samples collected in subsequent years.

\section{References}

Bruce, B.W., and McMahon, P.B., 1996, Shallow ground-water quality beneath a major urban center-Denver, Colorado, USA: Journal of Hydrology, v. 186, p. 129-151.

Delzer, G.C., Zogorski, J.S., Lopes, T.J., and Bosshart, R.L., 1996, Occurrence of the gasoline oxygenate MTBE and BTEX compounds in urban stormwater in the United States, 1991-1995: U.S. Geological Survey Water-Resources Investigations Report 96-4145, 6 p.

Horowitz, A.J., Demas, C.R., Fitzgerald, K.K., Miller, T.L., and Rickert, D.A., 1994, U.S. Geological Survey protocol for the collection and processing of surface-water samples for the subsequent determination of inorganic constituents in filtered water: U.S. Geological Survey Open-File Report 94-539, 59 p.

Koterba, M.T., Wilde, F.D., and Lapham, W.M., 1995, Ground-water datacollection protocols and procedures for the National Water-Quality Assessment Program-Collection and documentation of water-quality samples and related data: U.S. Geological Survey Open-File Report 95-399, 113 p.

Mueller, D.K., 1998, Quality of nutrient data from streams and ground water sampled during 1993-95-National WaterQuality Assessment Program: U.S. Geological Survey Open-File Report 98-276, 25 p.

Raese, J.W., Rose, D.L., and Sandstrom, M.W., 1995, U.S. Geological Survey laboratory method for methyl tert-butyl ether and other fuel oxygenates: U.S. Geological Survey Fact Sheet FS-21995, 4 p.

Rose, D.L., and Schroeder, M.P., 1995, Methods of analysis by the U.S. Geological Survey National Water Quality Laboratory-Determination of volatile organic compounds in water by purge and trap capillary gas chromatography/mass spectrometry: U.S. Geological Survey Open-File Report 94-708, $26 \mathrm{p}$.

Squillace, P.J., Zogorski, J.S., Wilber, W.G., and Price, C.V., 1996, Preliminary assessment of the occurrence and possible sources of MTBE in groundwater in the United States, 1993-1994: Environmental Science \& Technology, v. 30, no. 5, p. 1721-1730.
U.S. Environmental Protection Agency, 1992, Measurement of purgeable organic compounds in water by capillary-column gas chromatography/mass spectrometry, method 524.2 , revision 4.0: Cincinnati, Ohio, Environmental Monitoring Systems Laboratory, August 1992, $50 \mathrm{p}$.

Zogorski, J.S., Morduchowitz, Abraham, Baehr, A.L., Bauman, B.J., Conrad, D.L., Drew, R.T., Korte, N.E., Lapham, W.W., Pankow, J.F., and Washington, E.R., 1997, Fuel oxygenates and water quality, in Interagency assessment of oxygenated fuels: Washington, D.C., Office of Science and Technology Policy, Executive Office of the President, chap. 2, 122 p.

Zogorski, J.S., Delzer, G.C., Bender, D.A., Squillace, P.J., Lopes, T.J., Baehr, A.L., Stackelberg, P.E., Landmeyer, J.E., Boughton, C.J., Lico, M.S., Pankow, J.F., Johnson, R.L., and Thomson, N.R., 1998, MTBE--Summary of findings and research by the U.S. Geological Survey, in American Water Works Association Proceedings, Dallas, Texas: American Water Works Association, v. D, p. 287-309.

\section{- Gregory C. Delzer and James G. Setmire}

\section{Information}

Additional information on NAWQA and other USGS programs can be found by accessing the NAWQA "home page" on the World Wide Web at http://wwwr vares.er.usgs.gov/nawqa/nawqa_home.ht ml. Information on MTBE and other VOCs sampled by the NAWQA Program can be found at

http://wwwsd.cr.usgs.gov/nawqa/vocns

For information on this fact sheet, contact:

Gregory C. Delzer

U.S. Geological Survey

1608 Mountain View Road

Rapid City, SD 57702

(605) 355-4560 (ext. 230)

gcdelzer@usgs.gov

For information on the USGS national study of volatile organic compounds, contact:

John S. Zogorski

U.S. Geological Survey

1608 Mountain View Road

Rapid City, SD 57702

(605) 355-4560 (ext. 214)

jszogors@usgs.gov 